\title{
Avaliação morfológica de fibras eletrofiadas de policaprolactona em função do tipo de solvente
}

\author{
Morphological evaluation of electrospun \\ polycaprolactone fibers depending on \\ the type of solvent
}

Javier Mauricio Anaya Mancipe ${ }^{1,2}$, Marcos Lopes Dias ${ }^{2}$, Rossana Mara da Silva Moreira Thiré ${ }^{1}$

\footnotetext{
${ }^{1}$ Programa de Engenharia Metalúrgica e de Materiais - PEMM/COPPE/UFRJ CP: 68505, 21941-972, Rio de Janeiro, Rio de Janeiro, Brasil

${ }^{2}$ Instituto de Macromoléculas Professora Eloisa Mano - IMA/UFRJ, 21941-598, Rio de Janeiro, Rio de Janeiro, Brasil. e-mail: javier.anaya@metalmat.ufrj.br, mldias@ima.ufrj.br, rossana@metalmat.ufrj.br
}

\section{RESUMO}

Recentemente, estratégias da engenharia tecidual para o tratamento de feridas e queimaduras prevê o uso de biomateriais nanoestruturados capazes de facilitar a regeneração da pele e a cura das feridas. Um dos processos utilizados para a obtenção deste tipo de biomaterial é a eletrofiação. Por meio deste processo é possível formar filmes compostos por nanofibras poliméricas a partir de polímeros em solução e, assim, mimetizar a matriz extracelular da pele. Dentre os polímeros mais comumente utilizados, a policaprolactona (PCL) destaca-se por ser solúvel em diversos tipos de solventes. Este trabalho teve como objetivo principal avaliar a influência da condutividade elétrica de diferentes solventes na morfologia de fibras de PCL produzidas por eletrofiação. Também foi estudado o efeito da massa molar e da viscosidade da solução, assim como da vazão e da voltagem na morfologia das fibras. Foram usados como solventes: ácido acético (AC), ácido fórmico (AF), clorofórmio (CLO), diclorometano (DCM) e dimetilformamida (DMF). Foi possível obter fibras com diâmetros uniformes e livres de defeitos, como contas, utilizando o sistema de solventes DCM:DMF 70:30 (m/m), que, apesar de diminuir a massa molar do polímero durante a eletrofiação, gerou a melhor condição para a fiação do PCL. A condutividade elétrica influenciou diretamente as outras variáveis do processamento. Quando solventes com valores maiores de condutividade elétrica foram utilizados, foi necessária menor voltagem para a formação de fibras livre de defeitos. Os resultados mostraram que a condutividade elétrica da solução é uma variável de grande importância na escolha das condições experimentais para eletrofiação de PCL e, portanto, também deve ser melhor avaliada.

Palavras-chave: Eletrofiação, Policaprolactona, Nanofibras, Morfologia, Engenharia Tecidual.

\begin{abstract}
Recently, tissue engineering strategies for wound and burn treatment focuses on the use of nanostructures biomaterials capable of facilitating skin regeneration and wound healing. One of the processes used to obtain this type of biomaterial is electrospinning. This process allows to producing films composed of polymeric nanofibers from a polymeric solution and thus, mimics the skin extracellular matrix. Among the most commonly used polymers, polycaprolactone (PCL) can be highlighted due to its solubility in several types of solvents. This study aimed to evaluate the effect of electrical conductivity of different solvents on morphology of electrospun PCL fibers. The influence of molar mass and viscosity of solution as well as flow rate and voltage was also investigated. Acetic acid (AC), formic acid (AF), chloroform (CLO), dichloromethane (DCM) and dimethylformamide (DMF) were used as solvents. Fibers with uniform diameters and defect-free, such as beads, were obtained using the DCM:DMF 70:30 (m/m) solvent system. In spite of decreasing PCL molar mass during processing, this solvent system presented the best results for PCL electrospinning. Electrical conductivity directly influenced all studied variables. When solvent systems with higher electrical conductivity value were used, lower voltage was necessary to produce defect-free fibers.
\end{abstract}


Results indicated that solution electrical conductivity is a variable of great importance in condition selection of experimental parameters for PCL electrospinning and thus, should be better evaluated.

Keywords: Electrospinning, Polycaprolactone, Nanofibers, Morphology, tissue engineering.

\section{INTRODUÇÃO}

Nos últimos anos, muitos estudos têm sido conduzidos visando aplicações de estratégias da engenharia tecidual para o tratamento de feridas crônicas e agudas da pele, além de queimaduras [1]. Algumas técnicas da engenharia tecidual prevê a utilização de biomateriais capazes de facilitar a regeneração da pele e a cicatrização das feridas. A técnica de eletrofiação tem sido utilizada para produzir biomateriais nanoestruturados que formem uma rede tridimensional sobre a ferida, mimetizando, assim, a estrutura fibrilar da matriz extracelular da pele [2-4].

A eletrofiação é uma técnica comumente empregada para criar fibras sub-micrométricas usando polímeros fundidos ou em solução. A solução (ou o material fundido) é colocada em uma seringa ou capilar, a qual é ejetada por uma bomba de fluxo constante. A solução é, então, ejetada a partir da ponta de uma agulha submetida a uma voltagem que lhe é aplicada, até um coletor conectado ao fio terra, fazendo com que forças de atração e repulsão superem a tensão superficial da solução polimérica e a gota rompa em jatos finos numa trajetória cônica [6]. Esta trajetória (ou tempo de voo) é conhecida como distância percorrida e fornece condições especificas para que os solventes usados sejam evaporados, permitindo que as fibras se depositem completamente secas sobre a placa coletora, evitando a coalescência das fibras produzidas [5-7]. As fibras são coletadas aleatoriamente, formando estruturas conhecidas como filmes não tecidos.

Para conseguir criar este fenômeno de fiação, devem-se controlar algumas variáveis que dependem não só do processo de eletrofiação [8,9], como também das características da solução a ser usada e das condições ambientais. Diversos estudos têm sido realizados com o objetivo de entender a influência destas variáveis referentes ao processamento de eletrofiação, como a voltagem, a vazão, dentre outras [10-12]. No entanto, outras variáveis relacionadas ao solvente utilizado também podem influenciar o processo [13-16].

A policaprolactona é um poliéster alifático largamente aplicado na produção de biomateriais, devido a sua capacidade de degradação e baixa toxicidade, permitindo sua aplicação na engenharia tecidual e na produção de arcabouços usados como matrizes carregadoras de substâncias ativas (fármacos, fatores de crescimento entre outras) [17-19]. Diversos solventes têm sido empregados para o uso deste polímero na eletrofiação, com o propósito de criar as condições propícias para a formação dos fios [20]. Solventes como clorofórmio (CLO), dimetilformamida (DMF) e diclorometano (DCM) têm sido muito utilizados neste processamento [21]. No entanto, outros solventes orgânicos têm sido investigados na preparação de materiais com aplicação biológica, como o ácido acético e o ácido fórmico, e podem substituir os solventes halogenados considerados tóxicos para as células, além de apresentarem custo mais elevado. Dulnik et al. [22] propuseram uma mistura de $90 \%(\mathrm{~m} / \mathrm{m})$ de ácido acético e $10 \%(\mathrm{~m} / \mathrm{m})$ de ácido fórmico como solvente para a eletrofiação de nanofibras de PCL/gelatina e PCL/Colágeno. De acordo com estes autores, a aplicação desta mistura de ácidos reduziu custo de produção e a toxicidade do processo quando comparado com a eletrofiação utilizando solvente halogenado.

Apesar de diversos estudos correlacionarem a morfologia de fibras eletrofiadas de PCL com variáveis do processo de eletrofiação (vazão, tensão, etc.) e com variáveis próprias da solução a ser fiada, como a concentração do polímero e a viscosidade, as informações são muito limitadas quanto à correlação da condutividade elétrica da solução, ou especificamente do tipo do solvente utilizado, com a morfologia das fibras obtidas. A passagem das cargas elétricas através da solução é oferecida pela sua condutividade, favorecendo a disponibilidade destas cargas, promovendo uma interação de atração entre a solução polimérica e o coletor. Desta forma, pode-se supor que deva existir uma relação específica entre a voltagem, a quantidade de polímero disponível na ponta da agulha (vazão e massa molar) e as cargas elétricas, fazendo com que seja mantida a interação polímero-coletor de tal forma que supere a tensão superficial da solução criando um cone de Taylor estável que favoreça a formação de nanofibras contínuas com morfologia desejada.

Neste contexto, este trabalho teve como objetivo principal avaliar a influência da condutividade elétrica de diferentes solventes na morfologia de fibras de PCL produzidas por eletrofiação. Também foi estudado o efeito da massa molar e da viscosidade da solução, assim como da vazão e da voltagem na morfologia das fibras. Foram analisados: o sistema ácido acético/ácido fórmico (AC/AF) em diferentes proporções, uma concentração de ácido acético com clorofórmio (solventes comumente usados) e uma proporção de DMC/DMF (utilizado como controle). 


\section{MATERIAIS E MÉTODOS}

\subsection{Materiais}

Foi usada policaprolactona (PCL) em pellets da Sigma-Aldrich, Brasil $\left(\mathrm{M}_{\mathrm{n}}\right.$ : 70,000 - 90,000 g/mol; grau de hidrólise: 98\%, Código: 1001419114, lote \# MKBK2903V). Foram utilizados quatro diferentes solventes: ácido acético glacial (AC), ácido fórmico 98\% de pureza (AF), clorofórmio 98\% de pureza (CLO) e N,Ndimetilformamida (DMF), todos adquiridos da Vetec Química Fina LTDA, Rio de Janeiro, Brasil. Diclorometano (DCM) usado foi de procedência da Wako Pure Chemical Industries, Ltd., Osaka, Japan.

\subsection{Soluções poliméricas e eletrofiação}

Foram preparadas quatro soluções com $10 \% \mathrm{~m} / \mathrm{v}$ de PCL com os sistemas de solventes nas seguintes relações volumétricas: 1) 90AC/AF, $\mathrm{AC}: \mathrm{AF}=9: 1$; 2) 70AC/AF, $\mathrm{AC}: \mathrm{AF}=7: 3$; 3) 70CLO/AC, $\mathrm{CLO}: \mathrm{AC}=7: 3$; 4) 70DMF/DCM, DMF:DCM = 7:3. Todas as soluções foram preparadas sob agitação magnética por 12 horas a temperatura ambiente. Para o sistema de eletrofiação, foi usado para as quatro soluções num sistema horizontal composto por uma fonte de alta voltagem modelo PS/FC 60p02,0-1, uma bomba injetora para seringa KDS serie 100 e placa coletora de alumínio conectada a fio terra. As soluções foram eletrofiadas por um período de 4 horas, colocando $5 \mathrm{~mL}$ em uma seringa plástica com agulha metálica de 24 gauge. A distância percorrida usada foi de $15 \mathrm{~cm}$, a voltagem foi variada na faixa de $15-20 \mathrm{kV}$ e a vazão entre $0,5-$ $1,0 \mathrm{~mL} \cdot \mathrm{h}^{-1}$.

\subsection{Caracterização das soluções}

A massa molar numérica média, a massa molar ponderal média e a polidispersão foram medidas usando equipamento Shimadzu LC Solution. Para a análise foram pesadas $2 \mathrm{mg}$ de cada um dos filmes eletrofiados usando método de clorofórmio com um volume injetado aproximado de $2 \mu \mathrm{L}$. A viscosidade das soluções de PCL foram avaliadas usando viscosímetro do Brookfield. Usando temperatura de $25^{\circ} \mathrm{C}$ e Spindle de 25 a 60 rpm. Com o objetivo de avaliar a condutividade elétrica das soluções e a sua influência no processo de eletrofiação, foi utilizado Condutivímetro Digimed DM-32, utilizando eletrodo DMc - 100M, K: $10 \mathrm{~cm}^{-1}$, a sonda foi colocada em $30 \mathrm{~mL}$ das 4 soluções de PCL obtidas.

\subsection{Caracterização dos filmes}

\subsubsection{Microscopia Eletrônica de Varredura (MEV)}

A morfologia superficial dos filmes de PCL foi avaliada usando o equipamento Tescan VEGA3, usando aceleração de $15 \mathrm{kV}$. As amostras foram recobertas com ouro antes das análises. O tratamento das imagens obtidas foi feito usando o software Size Meter 1.1 para quantificar o diâmetro das fibras.

\subsubsection{Análise termogravimétrica (TGA)}

A estabilidade térmica e a perda de massa dos filmes de PCL foi avaliada por analise de termogravimetria usando um equipamento Shimadzu TGA-50 com faixa de aquecimento de $25^{\circ} \mathrm{C}$ a $700^{\circ} \mathrm{C}$ e taxa de aquecimento de $10^{\circ} \mathrm{C} / \mathrm{min}$ sob atmosfera de $\mathrm{N}_{2}$.

\subsubsection{Calorimetria Exploratória Diferencial (DSC)}

O comportamento térmico dos filmes eletrofiados e do polímero puro (pellets) foi avaliado pela análise de DSC, usando um equipamento Hitachi - DSC 7020 Thermal Analysis system. Nesta análise, usou-se aproximadamente $7 \mathrm{mg}$ dos filmes obtidos após de 5 horas de eletrofiação com cada um dos solventes estudados. Foram realizados dois ciclos de aquecimento e um de resfriamento com taxa de $10^{\circ} \mathrm{C} / \mathrm{min}$ e em atmosfera de nitrogênio com uma taxa de $50 \mathrm{~mL} / \mathrm{min}$. O primeiro ciclo de aquecimento foi conduzido de $25^{\circ} \mathrm{C}$ até $90^{\circ} \mathrm{C}$, seguido por um ciclo de resfriamento até $0^{\circ} \mathrm{C}$ e posterior aquecimento de $0{ }^{\circ} \mathrm{C}$ a $90^{\circ} \mathrm{C}$. $\mathrm{O}$ grau de cristalinidade relativo do material $(\mathrm{Xc})$ foi calculado pela Equação 1:

$$
X_{c}=\frac{\Delta H_{f}}{\Delta H_{f}^{o}}
$$


onde, $\Delta \mathrm{H}_{\mathrm{f}}$ é a medida da entalpia de fusão que corresponde à área do pico endotérmico da curva de DSC no $2^{\circ}$ aquecimento. $\Delta \mathrm{H}_{\mathrm{f}}^{\circ}$ é a entalpia de fusão para uma amostra de PCL com grau de cristalinidade de $100 \%$. Considerou-se $\Delta \mathrm{H}_{\mathrm{f}}^{\circ}$ igual a $151,7 \mathrm{~J} / \mathrm{g}$ [22].

\section{RESULTADOS}

Conforme já mencionado neste trabalho, o processo de eletrofiação é uma técnica usada para produção de fibras poliméricas com diâmetros na escala sub micrométrica. No entanto, em 2011, Robb e Lennox [23] descreveram que a morfologia das fibras fiadas é altamente influenciada e limitada não só por fatores relacionados ao processamento, mas também pelas variáveis relacionadas à solução utilizada. Fatores como a viscosidade, a tensão superficial, a condutividade elétrica, a massa molar do polímero entre outros, influenciam diretamente na produção de fibras continuas com diâmetros uniformes. Por este motivo, foi estudada, a influência dos solventes no processo de eletrofiação da policaprolactona (PCL).

Foram utilizados quatro sistemas solventes (solventes binários) neste estudo, fixando uma concentração de $10 \%(\mathrm{~m} / \mathrm{v})$ de PCL. O objetivando foi avaliar a morfologia das fibras obtidas por eletrofiação em função dos solventes usados e a sua influência com os parâmetros do processamento. Inicialmente realizou-se caracterização das quatro soluções propostas, medindo-se a viscosidade e a condutividade elétrica das soluções após de 12 horas de solubilização do PCL. Na Tabela 1, são apresentados os resultados referentes à viscosidade e à condutividade elétrica de cada um dos solventes usados.

Tabela 1: Viscosidade e condutividade das soluções com 10\% (m/v) de PCL em diferentes sistemas de solventes.

\begin{tabular}{l|l|l|l|l}
\hline \multicolumn{1}{c|}{ Variável } & \multicolumn{1}{|c|}{ 90AC/AF } & \multicolumn{1}{|c|}{ 70AC/AF } & \multicolumn{1}{|c}{ 70CLO/AC } & \multicolumn{1}{c}{ 70DMF/DCM } \\
\hline Viscosidade $(\mathrm{cP})$ & 57,60 & 19,20 & 105,60 & 28,80 \\
\hline Condutividade $(\mu \mathrm{S} / \mathrm{cm})$ & 345,0 & 589,7 & - & 116,70 \\
\hline
\end{tabular}

A interação polímero-solvente gera características particulares na solução capazes de permitir a formação de emaranhamento das cadeias poliméricas que geram variações na viscosidade como é observada na Tabela 1. A tabela mostra que a maior afinidade PCL-solvente foi apresentado com o sistema 70 CLO/AC, que mostra um valor da viscosidade elevada, em comparação com os outros sistemas de solventes utilizados. Porém, o sistema controle que gerou a morfologia desejada apresentou baixa viscosidade $(28,8 \mathrm{cP})$ e uma alta condutividade, condições importantes na eletrofiação, o que mostra condições estáveis das cadeias poliméricas no processo para a formação do cone de Taylor.

Por outro lado, obteve-se viscosidade baixa nas soluções obtidas usando AC como solvente. Porém, o caráter ácido dos solventes poderia estar ligado a esta diminuição significativa da viscosidade, atribuída a uma possível quebra da cadeia do PCL. Para analisar se o polímero apresentava essa degradação, foi realizada a avaliação da massa molar dos filmes fiados, usando as quatro soluções utilizadas. Também foi avaliada a influência da voltagem e da vazão sobre a morfologia das fibras produzidas usando essas quatro soluções de PCL $10 \%(\mathrm{~m} / \mathrm{v})$, usando os sistemas solvente bi-componentes. As imagens de MEV que apresentam as morfologias obtidas são mostradas nas Figuras 1 e 2. Considerando os quatro sistemas solvente, para avaliar a influência da voltagem, fixou-se uma vazão de $0,5 \mathrm{~mL} / \mathrm{h}$, variando a voltagem $(15,17$ e $20 \mathrm{kV}$ ) (Figura 1).

Utilizando-se a microscopia eletrônica de varredura (MEV) e o software Size Meter, avaliou-se o diâmetro das fibras, que apresentaram uma diminuição do tamanho médio de $134 \mathrm{~nm}( \pm 391)$ para $107 \mathrm{~nm}$ ( \pm $363 \mathrm{~nm}$ ) com o aumento da voltagem de 10 para $17 \mathrm{kV}$. No entanto, também foi observada a formação de contas nas fibras eletrofiadas para o sistema de solvente 90AC/AF, como é mostrado na Figura 1.

Observa-se que a morfologia das fibras obtidas com o sistema controle (70DCM/DMF) apresentou formação de fibras continuas, livre de contas e/ou defeitos como aglomerados para as condições de operação estudadas neste trabalho. Além disso, observa-se que para as voltagens de 15,17 e $20 \mathrm{kV}$, os diâmetros das fibras foram $608 \mathrm{~nm}( \pm 227,8 \mathrm{~nm}), 445,2 \mathrm{~nm}( \pm 166,7 \mathrm{~nm})$ e $344,7 \mathrm{~nm}( \pm 68 \mathrm{~nm})$, respetivamente. Isso indica que o aumento da voltagem é inversamente proporcional ao diâmetro gerado, o que é concordante com o reportado por HAIDER, et al., 2015 [24], onde é relatada a diminuição do diâmetro da fibra com o aumento da voltagem. O comportamento é atribuído ao alongamento da solução, devido a forças de repulsão de cargas dentro do jato polimérico.

Na Figura 1, foram ainda feitos registros para outras três soluções (90AC/AF, 70AC/AF e CLO/AC). Foram obtidas fibras homogêneas com grande número de defeitos nas condições trabalhadas. Esta variação na morfologia foi relacionada à influência dos solventes utilizados. Observa-se que as amostras eletrofiadas usando AC/AF como solvente (90AC/AF e 70AC/AF) geraram fibras finas, na escala nanométrica. No entanto, apresentaram grande quantidade de contas, as quais foram aumentando em tamanho e número com o incremento da voltagem. Esse comportamento pode ser atribuído à alta condutividade da solução, que 
promove a formação de contas, tornando o processo de eletrofiação similar ao processo conhecido como "electrospray". O comportamento é concordante com o relatado por ZHANG et al. (2019) [25], que mostrou a existência de uma relação direta entre a viscosidade, a tensão superficial e a condutividade com a voltagem aplicada, fazendo com que para uma determinada solução, deva existir uma condição na qual estas variáveis permitam a formação estável do cone de Taylor. O resultado é também de acordo com os resultados reportados por ENIS et al. (2016) [26], que demostraram que o ácido fórmico (AF), por ser um ácido com alto poder iônico, possui alta condutividade elétrica, fato também verificado pelos valores da Tabela 1, onde é evidenciado que com o aumento da concentração do AF de $10 \%$ para $30 \%$ em volume, gera um incremento aproximado de 17 vezes na condutividade elétrica para o sistema AC/AF. Esse fato também pode ser corroborado na Figura 1, considerando que para o sistema solvente AC/AF, para os mesmos valores na vazão e voltagem, com o aumento da quantidade de AF, foi obtida homogeneidade no diâmetro das contas, e o desaparecimento das contas quase por completo para as voltagens de 17 e $20 \mathrm{kV}$.

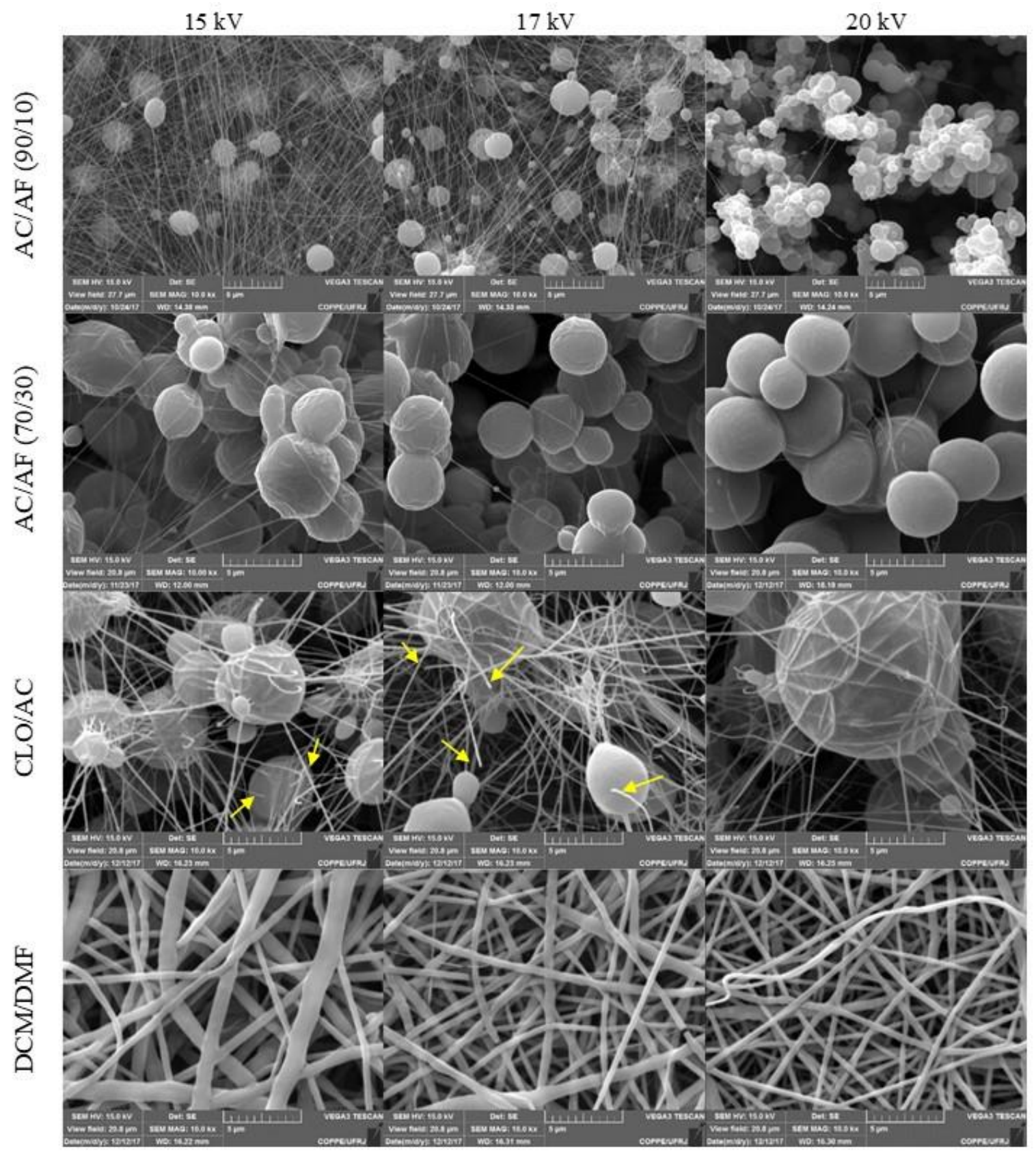

Figura 1: Imagens de MEV mostrando a Influência da voltagem em função do solvente sobre a morfologia das fibras eletrofiadas $(15,17$ e $20 \mathrm{kV})$.

Por outro lado, o sistema solvente formado por clorofórmio e ácido acético (CLO/AC) foi avaliado no 
processo de eletrofiação neste trabalho. Foi avaliada a influência na morfologia das fibras ao incorporar o AC no CLO, e demostrado que ocorreu uma desestabilização no cone de Taylor e no jato formado, que não foi registrado na literatura para sistemas de eletrofiação do PCL com CLO puro [27]. Este fenômeno foi atribuído ao aumento da condutividade elétrica da solução, o que possivelmente pode ter contribuído para a formação de micro contas, como mostrado na Figura 1. Esse fenômeno, pode ser atribuído à baixa condutividade elétrica da solução (70CLO/AC), já que o CLO, sendo um excelente solvente para o PCL, não possui uma constante dielétrica adequada para a fiação [28]. A adição do $30 \%$ de AC buscou o aumento da condutividade. Porém, com esta relação volumétrica (7:3), não se conseguiu atingir uma relação estável entre a condutividade elétrica, a tensão superficial e a voltagem aplicada. Observou-se que com este sistema solvente, foram obtidas fibras contendo contas, cujo tamanho aumentou com o aumento da voltagem de 17 $\mathrm{kV}$ para $20 \mathrm{kV}(3,91 \mu \mathrm{m})$, o que está de acordo com os resultados relatados em 2015 por HUANG et al. [29] e por KATSOGIANNIS et al [30].

\subsection{Influência da vazão na eletrofiação do PCL}

Como foi descrito por RAMAKRISHNA 5 [31], a vazão tem influência significativa na morfologia das nanoestruturas obtidas por eletrofiação, usando iguais condições de operação (voltagem, distância percorrida e concentração). A Figura 2 mostra imagens de MEV obtidas em três diferentes vazões (0,5; 0,75 e 1,0 $\mathrm{mL} / \mathrm{h}$ ), em função dos solventes usados no processo de eletrofiação, tomando uma voltagem fixa de $15 \mathrm{kV}$.

As fibras obtidas foram caracterizadas realizando a medição dos diâmetros para cada um dos quatro sistemas de solventes e também realizando avaliação qualitativa das fibras, levando em consideração características como os menores diâmetros, maior uniformidade das fibras, assim como a menor quantidade de defeitos (contas e/ou bolas). Os resultados são reportados na Tabela 2.

Tabela 2: Parâmetros para eletrofiação do PCL em função do tipo de solvente.

\begin{tabular}{l|l|l}
\hline \multicolumn{1}{c|}{ SOLVENTE } & \multicolumn{1}{|c|}{$\begin{array}{c}\text { VAZÃO } \\
(\mathbf{m L} / \mathbf{h})\end{array}$} & $\begin{array}{l}\text { VOLTAGEM } \\
(\mathbf{k V})\end{array}$ \\
\hline $\mathrm{AC} / \mathrm{AF}(9: 1)$ & 0,75 & 12,5 \\
\hline $\mathrm{AC} / \mathrm{AF}(7: 3)$ & 0,5 & 17 \\
\hline $\mathrm{CLO} / \mathrm{AC}(7 / 3)$ & 0,5 & 20 \\
\hline $\mathrm{DMF} / \mathrm{DCM}(7 / 3)$ & 0,5 & 17 \\
\hline
\end{tabular}

\subsection{Avaliação da massa molar do PCL eletrofiado}

As propriedades químicas dos solventes mostraram influência significativa na morfologia das fibras e/ou estruturas produzidas por eletrofiação, já que estes interferem nas variáveis do processo, conforme as propriedades da solução como viscosidade e condutividade, para soluções com a mesma concentração polimérica como tem sido mostrado neste trabalho.

A influência dos solventes sobre a massa molar das fibras eletrofiadas de PCL foram analisadas por cromatografia de permeação em gel (GPC). Os resultados massa molar numérica média $\left(M_{\mathrm{n}}\right)$, a massa molar ponderal média $\left(M_{\mathrm{w}}\right)$ e polidispersão $\left(M_{\mathrm{w}} / M_{\mathrm{n}}\right)$ do PCL após a eletrofiação e seu comparativo com o material que não foi submetido ao processo de eletrofiação (PCL) são mostrados na Tabela 3.

Tabela 3: $M_{w}, M_{n}$ e $M_{w} / M_{n}$ do PCL medida por GPC antes e após da eletrofiação em diferentes sistemas de solventes.

\begin{tabular}{l|l|l|l|l|l}
\hline & \multicolumn{1}{|c|}{ PCL } & \multicolumn{1}{c}{ 90AC/AF } & \multicolumn{1}{|c}{ 70AC/AF } & 70CLO/AC & 70DCM/DMF \\
\hline$M_{\mathrm{w}}$ & 229.100 & 41.500 & 143.400 & 201.300 & 55.600 \\
\hline$M_{\mathrm{n}}$ & 141.000 & 24.100 & 76.600 & 118.000 & 33.400 \\
\hline$M_{\mathrm{w}} / M_{\mathrm{n}}$ & 1,63 & 1,72 & 1,87 & 1,71 & 1,67 \\
\hline
\end{tabular}

De acordo com as micrografias da Figura 2, ocorreu a formação de fibras longas e livres de contas usando o sistema de solventes DCM/DMF, com uma diminuição em $M_{\mathrm{w}}$ próxima de 75,7\% (de 229.100 $\mathrm{g} / \mathrm{mol}$ para $55.600 \mathrm{~g} / \mathrm{mol}$ ) após a eletrofiação. 
A redução de $\mathrm{M}_{\mathrm{w}}$ em conjunto com a viscosidade da solução (28,8 cP) forneceram as condições necessárias para a geração de fibras contínuas com diâmetros uniformes e livres de contas e/ou defeitos. Além disso, observou-se uma diminuição evidente da massa molar do PCL quando este é solubilizado num solvente orgânico polar como o ácido acético, atribuída principalmente à quebra das ligações éster no PCL pela ação do ácido. A diminuição da concentração do AC no sistema solvente gerou cadeias mais longas de PCL após da eletrofiação, aumentando Mw de 41.500 para 143.400 g/mol quando a concentração de AC passou de 90 a $70 \%$, respetivamente.

A diminuição da massa molar parece ter tido uma relação direta com a viscosidade como era de esperar. As soluções com maiores viscosidades resultaram em polímeros com maior Mw, o que é concordante com os resultados de viscosidade apresentados na Tabela 1.

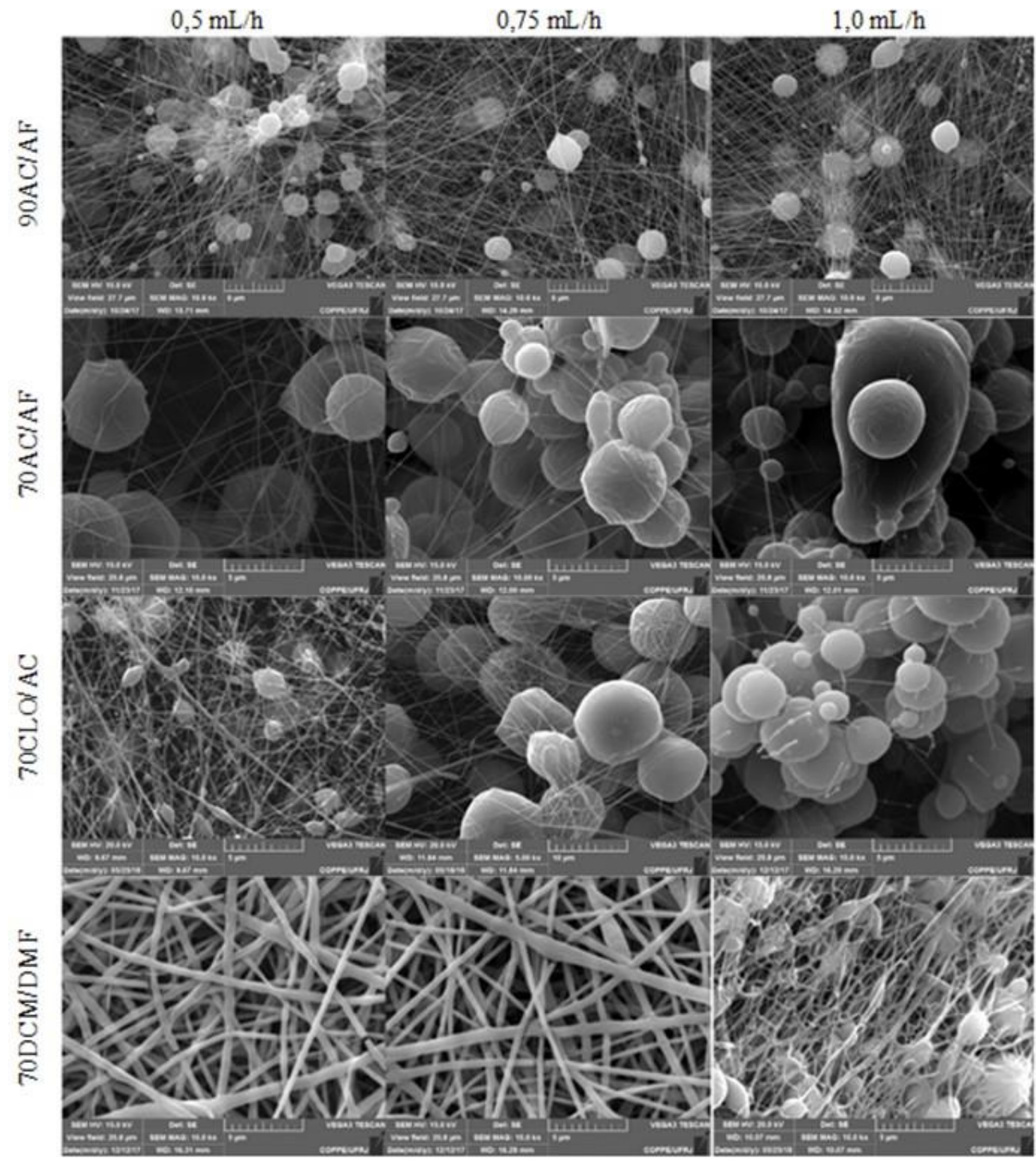

Figura 2: Imagens de MEV mostrando a influência da vazão na morfologia das fibras de PCL eletrofiadas segundo o sistema de solvente. Voltagem: $17 \mathrm{kV}$, distância percorrida: $15 \mathrm{~cm}$ e concentração: $10 \%(\mathrm{~m} / \mathrm{v})$. 


\subsection{Estabilidade térmica dos filmes}

O comportamento térmico dos filmes obtidos, avaliou as perdas de massa dos quatro filmes eletrofiados por análise termogravimétrica (TGA), comparando-os com o PCL em pellets usado neste trabalho. Os resultados são apresentados na Figura 3.

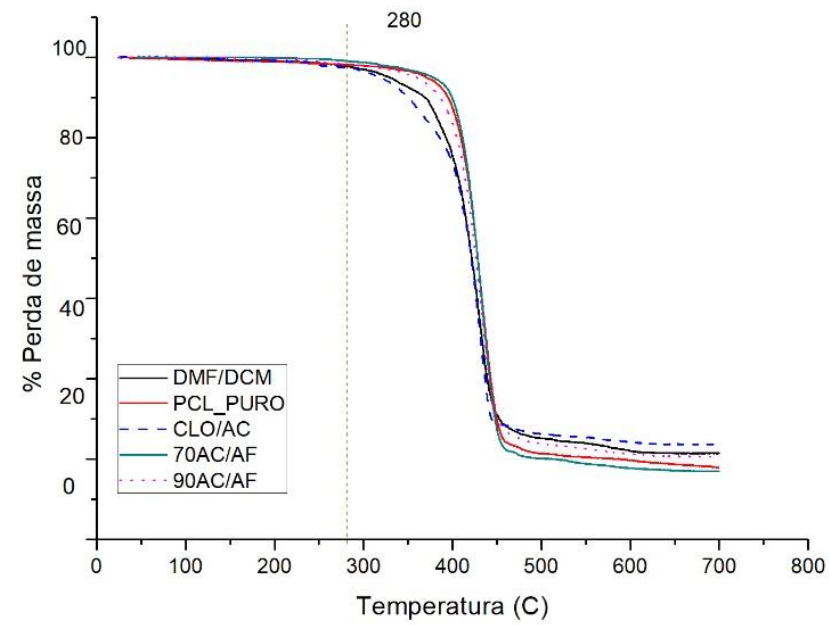

Figura 3: Curvas de TGA de PCL e de filmes eletrofiados de PCL

A degradação ocorre como um só evento de perda de massa, atribuída à decomposição do PCL na faixa de $382^{\circ} \mathrm{C}$ a $409^{\circ} \mathrm{C}$ [32]. Por outro lado, não foram observadas perdas significativas de massa em temperaturas inferiores aos $320^{\circ} \mathrm{C}$, faixa onde os solventes usados apresentam temperaturas de evaporação. Pode-se concluir que os solventes usados nas soluções eletrofiadas foram evaporados por completo no processo de eletrofiação. Este resultado é importante, pois pode ser um indício de que os materiais produzidos não seriam tóxicos às células.

\subsection{Transições térmicas e cristalinidade dos filmes}

As curvas calorimétricas, Figura 4 e Figura 5, mostraram que os filmes obtidos com cada um dos solventes binários avaliados no primeiro ciclo de aquecimento (Figura 4) geraram variações na entalpia requerida em suas transições térmicas tanto para o aquecimento como para seu resfriamento, estes valores foram quantificados e registrados na Tabela 5, com o objetivo de avaliar o grau de cristalinidade (segundo aquecimento) atingido no processamento.

A Figura 4 mostra que todas as fibras de PCL apresentam pico endotérmico atribuído à fusão e que as fibras preparadas com o sistema solvente AC/AF apresentaram a menor distribuição de tamanho de cristais, comprovada pelo pico de fusão mais estreito e mais intenso.

7

A

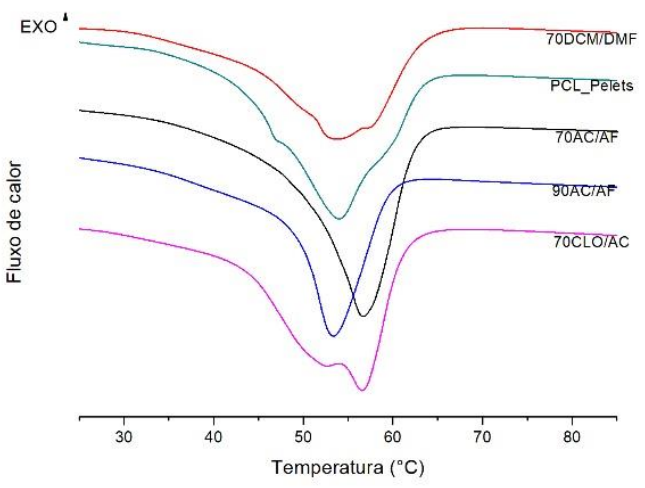

B

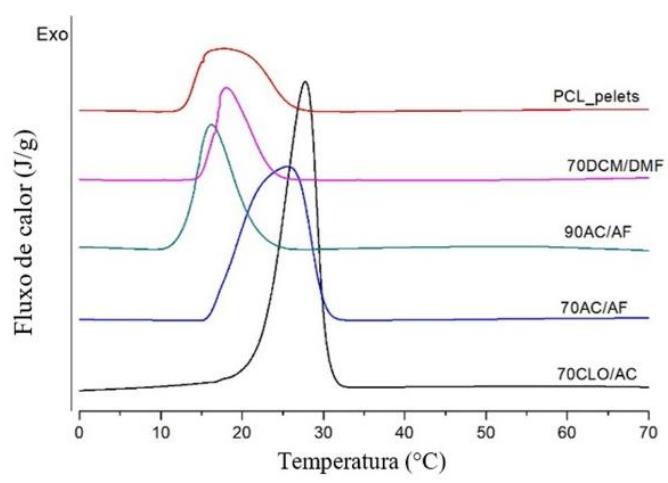

Figura 4: Curvas de DSC para as soluções de PCL usando os diversos sistemas de solventes usados. A) Primeiro ciclo de aquecimento. B) Ciclo de resfriamento. 
No primeiro aquecimento, observa-se que o pico de fusão para o PCL (pellets) mostra diferenças na fusão de seus cristais, apresentando pico alargado e com possibilidade da presença de três cristais de diferentes faixas de fusão. Os picos de fusão gerados para as fibras obtidas com solventes 90AC/AF e $70 \mathrm{AC} / \mathrm{AF}$ são mais estreitos, sugerindo que o processo de eletrofiação produziu cristais mais homogêneos. Essa diferença pode estar relacionada com a diminuição massa molar do PCL ocorrida durante o processo. No entanto, é observado um deslocamento do pico de fusão de $53^{\circ} \mathrm{C}$ para $57^{\circ} \mathrm{C} \mathrm{com} \mathrm{o} \mathrm{aumento} \mathrm{do} \mathrm{AC}$ na solução de solvente.

Tabela 4: Transições térmicas referentes aos ciclos de aquecimento e resfriamento do PCL para os diferentes sistemas de solventes.

\begin{tabular}{|c|c|c|c|c|c|c|c|}
\hline \multirow{2}{*}{ Amostra } & \multicolumn{2}{|c|}{$1 \%$ aquecimento } & \multicolumn{2}{|c|}{ Resfriamento } & \multicolumn{2}{|c|}{ 20 aquecimento } & \multirow{2}{*}{$\mathrm{X}_{\mathrm{c}}(\%)$} \\
\hline & $\mathrm{T}_{\mathrm{f}-1}\left({ }^{\circ} \mathrm{C}\right)$ & $\Delta H_{\mathrm{f}-1}(\mathrm{~J} / \mathrm{g})$ & $\mathrm{T}_{\mathrm{c}}\left({ }^{\circ} \mathrm{C}\right)$ & $\Delta H_{c}(J / g)$ & $\mathrm{T}_{\mathrm{f}-2}\left({ }^{\circ} \mathrm{C}\right)$ & $\Delta \mathrm{H}_{\mathrm{f}-2}\left({ }^{\circ} \mathrm{C}\right)$ & \\
\hline PCL_pellets & 54 & 23,1 & 18 & 21,2 & 48 & 13,8 & 15,2 \\
\hline $90 \mathrm{AC} / \mathrm{AF}$ & 53 & 19,1 & 16 & 17,4 & 49 & 13,0 & 12,6 \\
\hline $70 \mathrm{AC} / \mathrm{AF}$ & 57 & 22,0 & 26 & 20,2 & 49 & 18,9 & 14,5 \\
\hline $70 \mathrm{CLO} / \mathrm{AC}$ & 57 & 20,6 & 28 & 23,0 & 48 & 25,0 & 13,6 \\
\hline 70DCM/DMF & 54 & 19,6 & 18 & 17,9 & 52 & 15,2 & 12,9 \\
\hline
\end{tabular}

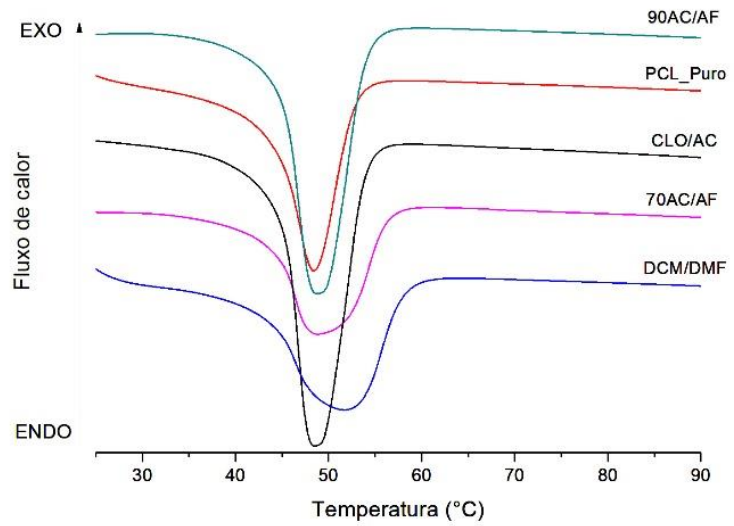

Figura 5: Curvas de DSC (segundo aquecimento) para o PCL para os filmes de PCL obtidos a partir de cada um dos sistemas solvente.

A estrutura produzida usando o sistema de solvente 70CLO/AC gerou pico de fusão bimodal, sugerindo a presença de dois tipos de cristais com perfeição cristalina diferentes. Conforme visto por MEV, as melhores fibras foram obtidas usando o sistema de solventes 70DCM/DMF. Entretanto, estas fibras apresentaram a menor cristalinidade, que pode ser atribuído ao processo de estiramento do material, quando pode ter ocorrido alta razão de evaporação dos solventes, o que faz com que os cristais não se formem adequadamente, gerando um material com maior quantidade de fase amorfa.

A cristalização para o polímero eletrofiado nos quatro solventes foi estudada no estágio de resfriamento entre 100 e $0^{\circ} \mathrm{C}$. Observou-se um deslocamento da temperatura de cristalização (Tc) de $18^{\circ} \mathrm{C}$ para o PCL em pellets para $28^{\circ} \mathrm{C}$ para o PCL que havia sido eletrofiado na solução de 70CLO/AC. Este deslocamento foi atribuído principalmente a variações da massa molar do polímero durante a eletrofiação, o que é concordante com o reportado por diferentes autores [12, 33, 34]. Polímeros com massas molares menores apresentam maior facilidade vibracional devido ao requerimento energético para que estas cadeias consigam escoar e finamente ser degradas, mostrando menor estabilidade térmica, como é o caso para o PCL eletrofiado usando o solvente 70CLO/AC.

\section{CONCLUSÕES}

Constatou-se que a massa molar, a viscosidade e a condutividade elétrica dos solventes possuem influência direta na morfologia das fibras. Foi possível obter fibras de diâmetros homogêneos utilizando o sistema de solventes 70DCM/DMF, que apesar de diminuir a massa molar do polímero durante a eletrofiação, gerou a melhor condição para a fiação do PCL. Apesar de ser utilizado por alguns autores como solvente para eletrofiação de PCL, o uso de ácido acético como componente do sistema de solventes, diminuiu a viscosidade da solução e a massa molar do polímero após o processo de eletrofiação, produzindo fibras finas com presença de micro contas. A cristalinidade das fibras eletrofiadas variou para os diferentes sistemas de 
solventes usados, devido à diminuição da massa molar, que permitiu diferentes rearranjos das cadeias em cristalitos de diferentes graus de perfeição. Apesar de ser uma alternativa aos solventes halogenados, a concentração de ácido acético usada neste trabalho não atingiu os valores necessários para a formação de fibras contínuas com morfologia adequada em nenhum dos sistemas de solventes testados (90AC/AF, 70AC/AF e 70CLO/AC), fato que foi atribuído a um excesso de cargas na solução, devido ao caráter ácido do solvente. Além disso, o uso do ácido acético como solvente do PCL degradou o polímero durante a eletrofiação.

Foi observado que a condutividade elétrica influenciou diretamente as outras variáveis do processamento, como vazão e voltagem. Quando solventes com valores maiores de condutividade foram utilizados, foi necessária menor voltagem para a formação de fibras livre de defeitos. Os resultados mostraram, portanto, que a condutividade elétrica da solução é uma variável de grande importância na escolha das condições de eletrofiação a serem utilizadas.

\section{AGRADECIMENTOS}

Os autores agradecem a colaboração do laboratório de microscopia do Programa de Engrenharia Metalúrgica e de materiais (PEMM/COPPE/UFRJ); ao Laboratório de Macromoléculas e coloides na indústria do Petróleo (LMCP) do instituto de Macromoléculas Professora Eloisa Mano (IMA-UFRJ) e ao laboratório Multiusuário do programa PEMM/COPPE/UFRJ pelas análises de caracterização das amostras desenvolvidas neste trabalho.

\section{BIBLIOGRAFIA}

[1] MORRIS, A. H., STAMER, D. K., KYRIAKIDES, T. R. "The host response to naturally - Derived extracellular matrix biomaterials”, Seminars in Immunology, v.1, pp. 72-91, 2017.

[2] CHAN, B.P., LEONG, K.W. "Scaffolding in tissue engineering: General approaches and tissue-specific considerations", European Spine Journal, v. 17, n.4, pp. 467-479, 2008.

[3] JIANG, T., CARBONE E. J., LO, K.W. H., et al., "Electrospinning of polymer nanofibers for tissue regeneration", Progress in Polymer Science, v. 46, pp. 1-24, 2015.

[4] NOROUZI, M., BOROUJENI, S. M., OMIDVARKORDSHOULI, N., et al., "Advances in Skin Regeneration: Application of Electrospun Scaffolds”, Advance Healthcare Materials., v. 4, pp. 1114-1133, 2015 .

[5] NISTA, S., PERES, L., D’ÁVILA, M., et al., "Nanostructured Membranes Based on Cellulose Acetate Obtained by Electrospinning, Part 1: Study of the Best Solvents and Conditions by Design of Experiments", Journal of Applied Polymer Science, v. 126, pp. E70-E80, 2012.

[6] FERNANDES, P. R., BÁRTOLO, P. J. (eds.), Advances on Modeling in Tissue Engineering, Computational Methods in Applied Sciences 20, Springer Science Business Media B.V. 2011.

[7] DUQUE, L. M., RODRIGUEZ, L., LÓPEZ, M. "Electrospinning: La era de las nano fibras", Rev. Iberoamericana de Polímeros. v. 14, n. 1, pp. 10-27, 2013.

[8] LEVITT, A. S. VALLETT, R., DION, G., et al., "Effect of electrospinning processing variables on polyacrylonitrile nanoyarns", J. Appl. Polym. Sci., v. 135, pp. 1-9, 2018.

[9] PEZZIN, S. H., OLALlA, A. S., TORRES, E. G., et al., "Preparação de membranas de PHB por eletrofiação e caracterização para aplicações em engenharia tecidual”, RevistaMatéria, v. 24, n. 04, pp. 1-8, 2018.

[10] BHARDWAJ, N., KUNDU, S. C. "Electrospinning: A fascinating fiber fabrication technique", Biotechnology Advances, v. 28, n. 3, pp. 325-347, 2010.

[11] SUN, B., LONG, Y.Z., ZHANG, H.D., et al., "Advances in three-dimensional nanofibrous macrostructures via electrospinning”, Prog. Polym. Sci. 39, v.5, pp. 862-890. 2014.

[12] ZHU, M., HAN, J., WANG, F., et al., "Electrospun Nanofibers Membranes for Effective Air Filtration", Macromolecular Materials and Engineering, v. 302, pp. 1-27, 2017.

[13] GIL-CASTELL, O., BADIA, J.D., STRÖMBERG, E., et al., "Effect of the dissolution time into an acid hydrolytic solvent to Taylor electrospun nanofibrous polycaprolactone scaffolds", European Polymer Journal, v. 87, pp. 174-187, 2017.

[14] DIAS, J., BARTOLO, P. "Morphological characteristics of electrospun PCL meshes - the influence of solvent type and concentration”, Procedia CIRP, v. 05, pp. 216 - 221, 2013. 
[15] VAN DER SCHUEREN, L., SCHOENMAKER, B., KALAOGLU, Ö. I. et al., "An alternative solvent system for the steady state electrospinning of polycaprolactone", European Polymer Journal, v. 47, pp. $1256-1263,2011$

[16] NASOURI, K., SHOUSHTARI, A. M., MOJTAHEDI, M. R. M. "Evaluation of Effective Electrospinning Parameters Controlling Polyvinylpyrrolidone Nanofibers Surface Morphology via Response Surface Methodology". Fibers and Polymers, v.16, n.9, pp. 1941-1954, 2015.

[17] LI, W. J., MAUCK, R. L., COOPER, J. A., et al., "Engineering controllable anisotropy in electrospun biodegradable nanofibrous scaffolds for musculoskeletal tissue engineering", Biomaterials, v. 29, n. 8, pp. 1686-1693, 2008.

[18] SIDDIQUI, N., ASAWA, S., BIRRU, B., et al., "PCL-Based composite scaffold matrices for tissue engineering applications", Molecular Biotechnology, v. 60, n. 7, pp. 506-532, 2018.

[19] HOSSEINKAZEMI, H., BIAZAR, E., BONAKDAR, S., et al., "Modification of PCL Electrospun Nanofibrous Mat with Calendula officinalis Extract for Improved Interaction with Cells", International Journal of Polymeric Materials and Polymeric Biomaterials, v. 64, pp. 459-464, 2015.

[20] HAIDER, A., HAIDER, S., KANG, I. K. "A comprehensive review summarizing the effect of electrospinning parameters and potential applications of nanofibers in biomedical and biotechnology", v. 11, n. 8, pp. 1165-1188, 2018.

[21] HU, J., PRABHAKARAN, M. P., DING, X., et al., "Emulsion electrospinning of polycaprolactone: influence of surfactant type towards the scaffold properties", Journal of Biomaterials Science, polymer edition, v.26, n.1, pp. 57-75, 2015.

[22] DULNIK, J., DENIS P., SAJKIEWICZ, P., et al., "Biodegradation of bicomponent PCL/gelatin and PCL/collagen nanofibers electrospun from alternative solvent system", Polymer Degradation and Stability, v. 130, pp. 10-21, 2016.

[23] ROBB, B., LENNOX, B. "The electrospinning process, conditions and control", Electrospinning for tissue regeneration, v. 4, pp. 73-108, 2017.

[24] HAIDER, S., HAIDER, A., AHMED, A., et al., "Electrospun Nanofibers affinity membranes for water hazards remediation", Nova Science Publishers, v. 44, pp. 81-111, $2015 \mathrm{~b}$.

[25] ZHANG, S., CAMPAGNE, C., SALAUN, F. "Influence of solvent selection in the electrospraying process of polycaprolactone", Applied Sciences, v. 9, n. 402, pp. 1-36, 2019.

[26] ENIS, I. Y., VOJTECH, J. SADIKOGLU, T. G. "Alternative solvent systems for polycaprolactone nanowebs via electrospinning”, Journal of industrial textiles, v. 47, n. 1, pp. 57-70, 2016.

[27] KIM, J. H., JANG, J., JEONG, Y. H., et al., "Fabrication of a Nanofibrous mat with a human skin pattern", Langmuir, v. 31, n. 1, pp. 424-431, 2014.

[28] HAROOSH, H. J., CHAUDHARY, D. S., DONG, Y. "Electrospun PLA/PCL fibers with tubular nanoclay: Morphological and structural analysis", Journal of applied polymer science, v. 124, n. 5, pp. 39303939, 2011

[29] HUANG, Y-S., KUO, C., HUANG, C., et al., "Novel highly aligned, double-layered, hollow fibrous polycarbonate membranes with a perfectly tightly packed pentagonal pore structure fabricated using the electrospinning process", Royal society Chemistry, v.5, pp. 88857-88865, 2015.

[30] KATSOGIANNIS, K. A. G., VLADiSAVlJEVIC, G. T., GEORGIADOU, S. "Porous electrospun polycaprolactone (PCL) fibers by phase separation", European Polymer Journal, v.69, pp. 284-295, 2015.

[31] RAMAKRISHNA, S., FUJIHARA, K., TEO, W., LIM, T., MA, Z. "An introduction to electrospinning and nanofibers", World Scientific Publishing Co. Pte. Ltd. Singapore. 2005.

[32] MOHAMED, A., FINKENSTADT, V. L., GORDON, S. H., et al., "Thermal properties of PCL/gluten bioblends characterized by TGA, DSC, SEM, and infrared-pas", Journal of applied polymer science, v. 110, n. 5, pp. 3256-3266, 2008.

[33] ELZEIN, T., NASSER, M. E., DELAITE, C., et al., "FTIR study of polycaprolactone chain organization at interfaces", Journal of colloid and interface Science, v. 273, pp. 381 -387, 2004.

[34] SPERENZA, V., SORRENTINO, A., PANTANI, R., et al., "Characterization of the polycaprolactone melt crystallization: complementary optical microscopy, DSC, and AFM studies", The Scientific World Journal, v. 1, pp. 1-9, 2014. 


\section{ORCID}

Javier Mauricio Anaya Mancipe

https://orcid.org/0000-0001-7898-3471

Marcos Lopes Dias

https://orcid.org/0000-0003-1891-7530

Rossana Mara da Silva Moreira Thiré

https://orcid.org/0000-0003-0026-5431 